\title{
THE RAMSEY NUMBERS FOR DISJOINT UNION OF STARS
}

\author{
HASMAWATI
}

\begin{abstract}
Department of Mathematics, Faculty of Mathematics and Natural Sciences, Universitas Hasanuddin (UNHAS), Jln. Perintis Kemerdekaan Km 10 Makassar 90245, Indonesia, hasma_ba@yahoo.com
\end{abstract}

\begin{abstract}
The Ramsey number for a graph $G$ versus a graph $H$, denoted by $R(G, H)$, is the smallest positive integer $n$ such that for any graph $F$ of order $n$, either $F$ contains $G$ as a subgraph or $\bar{F}$ contains $H$ as a subgraph. In this paper, we investigate the Ramsey numbers for union of stars versus small cycle and small wheel. We show that if $n_{i} \geq 3$ for $i=1,2, \ldots, k$ and $n_{i} \geq n_{i+1} \geq \sqrt{n_{i}}-2$, then $R\left(\bigcup_{i=1}^{k} S_{1+n_{i}}, C_{4}\right)=\sum_{i=1}^{k} n_{i}+k+1$ for $k \geq 2$. Furthermore, we show that if $n_{i}$ is odd and $2 n_{i+1} \geq n_{i}$ for every $i$, then $R\left(\bigcup_{i=1}^{k} S_{n_{i}}, W_{4}\right)=R\left(S_{n_{k}}, W_{4}\right)+\sum_{i=1}^{k-1} n_{i}$ for $k \geq 1$.
\end{abstract}

Key words and Phrases: Ramsey number, cycle, wheel.

Abstrak. Bilangan Ramsey untuk graf $G$ terhadap graf $H$, dinotasikan oleh $R(G, H)$, yakni bilangan bulat terkecil $n$ sehingga sembarang graf $F$ berorde $n$, memenuhi $F$ memuat $G$ sebagai suatu subgraf atau $\bar{F}$ memuat $H$ sebagai suatu subgraf. Dalam makalah ini, dikaji bilangan Ramsey untuk gabungan saling lepas bintang terhadap siklus berorde empat dan roda berorde lima. Kita akan menunjukkan bahwa apabila $n_{i} \geq 3, i=1,2, \ldots, k$ dan $n_{i} \geq n_{i+1} \geq \sqrt{n_{i}}-2$, maka $R\left(\bigcup_{i=1}^{k} S_{1+n_{i}}, C_{4}\right)=\sum_{i=1}^{k} n_{i}+k+1$ untuk $k \geq 2$. Selanjutnya, ditunjukkan bahwa jika $n_{i}$ ganjil dan $2 n_{i+1} \geq n_{i}$ untuk setiap $i$, maka $R\left(\bigcup_{i=1}^{k} S_{n_{i}}, W_{4}\right)=$ $R\left(S_{n_{k}}, W_{4}\right)+\sum_{i=1}^{k-1} n_{i}$ dengan $k \geq 1$.

Kata kunci: Bilangan Ramsey, siklus, roda.

\section{Introduction}

For given graphs $G$ and $H$, the Ramsey number $R(G, H)$ is defined as the smallest positive integer $n$ such that for any graph $F$ of order $n$, either $F$ contains

2000 Mathematics Subject Classification:

Received: 08-10-2010, accepted: 06-12-2010 
$G$ or $\bar{F}$ contains $H$, where $\bar{F}$ is the complement of $F$. Chvátal and Harary [4] established a useful lower bound for finding the exact Ramsey numbers $R(G, H)$, namely $R(G, H) \geq(\chi(G)-1)(C(H)-1)+1$, where $\chi(G)$ is the chromatic number of $G$ and $C(H)$ is the number of vertices of the largest component of $H$. We present some notations used in this note. Let $G$ be any graph with the vertex set $V(G)$ and the edge set $E(G)$. The order of $G$, denoted by $|G|$, is the number of its vertices. The graph $\bar{G}$, the complement of $G$, is obtained from the complete graph on $|V(G)|$ vertices by deleting the edges of $G$. A graph $F=\left(V^{\prime}, E^{\prime}\right)$ is a subgraph of $G$ if $V^{\prime} \subseteq V(G)$ and $E^{\prime} \subseteq E(G)$. For $S \subseteq V(G), G[S]$ represents the subgraph induced by $S$ in $G$. If $G$ is a graph and $H$ is a subgraph of $G$, then denote $G[V(G) \backslash V(H)]$ by $G \backslash H$. For $v \in V(G)$ and $S \subset V(G)$, the neighborhood $N_{S}(v)$ is the set of vertices in $S$ which are adjacent to $v$. Furthermore, we define $N_{S}[v]=N_{S}(v) \cup\{v\}$. If $S=V(G)$, then we use $N(v)$ and $N[v]$ instead of $N_{V(G)}(v)$ and $N_{V(G)}[v]$, respectively. The degree of a vertex $v$ in $G$ is denoted by $d_{G}(v)$. Let $S_{n}$ be a star on $n$ vertices and $C_{m}$ be a cycle on $m$ vertices. We denote the complete bipartite whose partite sets are of order $n$ and $p$ by $K_{n, p}$.

Since then the Ramsey numbers $R(G, H)$ for many combinations of graphs $G$ and $H$ have been extensively studied by various authours, see a nice survey paper [8]. In particular, the Ramsey numbers for combinations involving union of stars have also been investigated. Let $S_{n}$ be a star of $n$ vertices and $W_{m}$ a wheel with $m$ spokes.

For a combination of stars with wheels, Surahmat et al. [9] determined the Ramsey numbers for large stars versus small wheels. Their result is as follows.

Theorem A. (Surahmat and E. T. Baskoro, [9]) For $n \geq 3$,

$$
R\left(S_{n}, W_{4}\right)=\left\{\begin{array}{l}
2 n+1, \text { if } n \text { is even } \\
2 n-1, \text { if } n \text { is odd. }
\end{array}\right.
$$

Parsons in [7] considered about the Ramsey numbers for stars versus cycles as presented in Theorem .

Theorem B. (Parsons's upper bound, [7]) For $p \geq 2, R\left(S_{1+p}, C_{4}\right) \leq p+\sqrt{p}+1$.

Hasmawati et al. in [6] and [5] proved that $R\left(S_{6}, C_{4}\right)=8$, and $R\left(S_{6}, K_{2, m}\right)=13$ for $m=5$ or 6 respectively.

Let $G$ be a graph. The number of vertices in a maximum independent set of $G$ denoted by $\alpha_{0}(G)$, and the union of $s$ vertices-disjoint copies of $G$ denoted by $s G$. S. A. Burr et al. in [3], showed that if the graph $G$ has $n_{1}$ vertices and the graph $H$ has $n_{2}$ vertices, then 


$$
n_{1} s+n_{2} t-D \leq R(s G, t H) \leq n_{1} s+n_{2} t-D+k,
$$

where $D=\min \left\{s \alpha_{0}(G), t \alpha_{0}(H)\right\}$ and $k$ is a constant depending only on $G$ and $H$. Recently, Baskoro et al. in [1] determined the Ramsey numbers for multiple copies of a star versus a wheel. Their results are given in the next theorem.

Theorem C. [1] For $n \geq 3$,

$$
R\left(k S_{n}, W_{4}\right)=\left\{\begin{array}{l}
(k+1) n, \quad \text { if } n \text { is even and } k \geq 2 \\
(k+1) n-1, \quad \text { if } n \text { is odd and } k \geq 1
\end{array}\right.
$$

\section{Main Results}

In this paper, we study the Ramsey numbers for disjoint union of stars versus small cycle and small wheel. The results are presented in the next two theorems. Before present these theorems let us present the lemma as follow.

Lemma 2.1. For $k \geq 2$ and $n_{i} \geq 3$ for every $i$,

$$
R\left(\bigcup_{i=1}^{k} S_{n_{i}+1}, C_{4}\right) \geq \sum_{i=1}^{k} n_{i}+k+1
$$

Proof. Let $n_{i} \geq 3$ for every $i$ and $k \geq 2$. Consider $F \cong K_{\sum_{i=1}^{k}\left(n_{i}+1\right)-1} \cup K_{1}$. Graph $F$ has $\sum_{i=1}^{k} n_{i}+k$ vertices, however it contains no $\bigcup_{i=1}^{k} S_{1+n_{i}}$. It is easy to see that $\bar{F}$ is isomorphic with $K_{1, \sum_{i=1}^{k}\left(n_{i}+1\right)-1}$. So, $\bar{F}$ contains no $C_{4}$. Hence, $R\left(\bigcup_{i=1}^{k} S_{1+n_{i}}, C_{4}\right) \geq \sum_{i=1}^{k}\left(n_{i}+1\right)+1$.

Theorem 2.2. Let $n_{i} \geq 3$ for $i=1,2, \ldots, k$. If $n_{i} \geq n_{i+1} \geq \sqrt{n_{i}}-2$, then $R\left(\bigcup_{i=1}^{k} S_{1+n_{i}}, C_{4}\right)=\sum_{i=1}^{k} n_{i}+k+1$ for $k \geq 2$.

Proof. For $k=2$, we show that $R\left(S_{1+n_{2}} \cup S_{1+n_{2}}, C_{4}\right)=n_{1}+n_{2}+3$. Let $F_{1}$ be a graph of order $n_{1}+n_{2}+3$ for $n_{1}, n_{2} \geq 3$. Suppose $\bar{F}_{1}$ contains no $C_{4}$. Since $n_{2}+2 \geq \sqrt{n}_{1}$, then $\left|F_{1}\right| \geq n_{1}+\sqrt{n}_{1}+1$. By Parsons's upper bound, we have $\left|F_{1}\right| \geq R\left(S_{1+n_{1}}, C_{4}\right)$ for $n_{1} \geq 3$. Thus $F_{1} \supseteq S_{1+n_{1}}$.

Let $V\left(S_{1+n_{1}}\right)=\left\{v_{0}, \ldots, v_{n_{1}}\right\}$ with center $v_{0}$. Write $T=F_{1} \backslash S_{1+n_{1}}$. Thus $|T|=$ $n_{2}+2$. If there exists $v \in T$ with $d_{T}(v) \geq n_{2}$, then $T$ contains $S_{1+n_{2}}$. Hence $F_{1}$ contains $S_{1+n_{2}} \cup S_{1+n_{2}}$. Therefore, we assume that for every vertex $v \in T$, $d_{T}(v) \leq\left(n_{2}-1\right)$.

Let $u$ be any vertex in $T$. Write $Q=T \backslash N_{T}[u]$. Clearly, $|Q| \geq 2$. Observe that if there exists $s \in F_{1}$ where $s \neq u$ which is not adjacent to at least two vertices in $Q$, then $\overline{F_{1}}[\{s, u\} \cup Q]$ will contains $C_{4}$, a contradiction. Hence, for the remaining of the proof we will use the following assumption. 
Assumption 1 . Every vertex $s \in F_{1}, s \neq u$ is not adjacent to at most one vertex in $Q$.

Let $u$ be adjacent to at least $n_{2}-\left|N_{T}(u)\right|$ vertices in $S_{1+n_{1}}-v_{0}$, call them $v_{1}, \ldots, v_{n_{2}-\left|N_{T}(u)\right|}$. Observe that $n_{2}-\left|N_{T}(u)\right|=|Q|-1$. By Assumption 1, vertex $v_{0}$ is adjacent to at least $|Q|-1$ vertices in $Q$, namely $q_{1}, \ldots, q_{n_{2}-\left|N_{T}(u)\right|}$. Then we have two new complete bipartite graphs, namely $S_{1+n_{1}}^{\prime}$ and $S_{1+n_{2}}$, where

$$
V\left(S_{1+n_{1}}^{\prime}\right)=\left(S_{1+n_{1}} \backslash\left\{v_{1}, \ldots, v_{n_{2}-\left|N_{T}(u)\right|}\right\}\right) \cup\left\{q_{1}, \ldots, q_{n_{2}-\left|N_{T}(u)\right|}\right\}
$$

with $v_{0}$ as the center and

$$
V\left(S_{1+n_{2}}\right)=N_{T}[u] \cup\left\{v_{1}, \ldots, v_{n_{2}-\left|N_{T}(u)\right|}\right\}
$$

with $u$ as the center. Hence, we have $F_{1} \supseteq S_{1+n_{2}} \cup S_{1+n_{2}}$.

Now, we assume that $u$ is adjacent to at most $n_{2}-\left|N_{T}(u)\right|-1$ vertices in $S_{1+n_{1}}-v_{0}$. This means $u$ is not adjacent to at least $\left|N_{T}(u)\right|+1$ vertices in $S_{1+n_{1}}-v_{0}$. Let $Y=\left\{y \in S_{1+n_{1}}-v_{0}: y u \notin E\left(F_{1}\right)\right\}$. Then $|Y| \geq\left|N_{T}(u)\right|+1 \geq 1$.

Suppose for every $y \in Y$, there exists $r \in N_{T}(u)$ such that $y r \notin E\left(F_{1}\right)$. Since $\left|N_{T}(u)\right|<|Y|$, then there exists $r_{0} \in N_{T}(u)$ so that $r_{0}$ is not adjacent to at least two vertices in $Y$, say $y_{1}$ and $y_{2}$. This implies, $\overline{F_{1}}\left[u, r_{0}, y_{1}, y_{2}\right]$ forms a $C_{4}$, a contradiction. Hence, there exists $y^{\prime} \in Y$ so that $y^{\prime}$ is adjacent to all vertices in $N_{T}(u)$. Furthermore, by Assumption 1 we have that $\left|N_{T}\left(y^{\prime}\right)\right| \geq\left|N_{T}(u)\right|+|Q|-1=|T|-2=n_{2}$.

Let $q^{\prime}$ be the vertex in $Q$ which is not adjacent with $y^{\prime}$. If $v_{0} u \notin E\left(F_{1}\right)$, then $v_{0}$ must be adjacent to $q^{\prime}$. (Otherwise $\bar{F}$ would contain $C_{4}$ formed by $\left\{v_{0}, y^{\prime}, q^{\prime}, u\right\}$ ). Now we have two new stars, namely $S_{1+n_{1}}^{1}$ and $S_{1+n_{2}}^{2}$, where $V\left(S_{1+n_{1}}^{1}\right)=N_{T}\left[y^{\prime}\right]$ with $y^{\prime}$ as the center and $V\left(S_{1+n_{2}}^{2}\right)=\left(S_{1+n_{1}} \backslash\left\{y^{\prime}\right\}\right) \cup\left\{q^{\prime}\right\}$. If $v_{0} u \in E\left(F_{1}\right)$, then we also have two new stars. The first one is $S_{1+n_{1}}^{1}$ as in the previous case and the second one is $S_{1+n_{2}}^{3}$ where $V\left(S_{1+n_{2}}^{3}\right)=\left(S_{1+n_{1}} \backslash\left\{y^{\prime}\right\}\right) \cup\{u\}$ with $v_{0}$ as the center. In case that $y^{\prime}$ is adjacent with all vertices in $Q$ and $v_{0} u \notin E\left(F_{1}\right)$, then the second star is $S_{1+n_{2}}^{4}$ where $V\left(S_{1+n_{2}}^{4}\right)=\left(S_{1+n_{1}} \backslash\left\{y^{\prime}\right\}\right) \cup\{q\}, q \in Q$ with $v_{0}$ as the center. The fact that $v_{0} q \in E\left(F_{1}\right)$ is guaranteed by Assumption 1 .

Therefore, we have $F_{1} \supseteq S_{1+n_{2}} \cup S_{1+n_{2}}$. Thus $R\left(S_{1+n_{2}} \cup S_{1+n_{2}}, C_{4}\right) \leq$ $n_{1}+n_{2}+3$. By Lemma 2.1 we have $R\left(S_{1+n_{2}} \cup S_{1+n_{2}}, C_{4}\right)=n_{1}+n_{2}+3$.

We assume the theorem holds for every $2 \leq r<k$. Let $F_{2}$ be a graph of order $\sum_{i=1}^{k} n_{i}+k+1$. Suppose $\bar{F}_{2}$ contains no $C_{4}$. We will show that $F_{2} \supseteq \bigcup_{i=1}^{k} S_{1+n_{i}}$. By induction hypothesis, $F_{2} \supseteq \bigcup_{i=1}^{k-1} S_{1+n_{i}}$. Write $B=F_{2} \backslash \bigcup_{i=1}^{k-2} S_{1+n_{i}}$ and $T^{\prime}=$ $F_{2}[B]$. Thus $\left|T^{\prime}\right|=n_{k-1}+n_{k}+3$. Since $\bar{T}^{\prime}$ contains no $C_{4}$ and its follows from the case $k=2$ that $T^{\prime}$ contains $S_{1+n_{k-1}} \cup S_{1+n_{k}}$. Hence $F_{2}$ contains $\bigcup_{i=1}^{k} S_{1+n_{i}}$. 
Thus we have $R\left(\bigcup_{i=1}^{k} S_{1+n_{i}}, C_{4}\right) \leq \bigcup_{i=1}^{k} n_{i}+k+1$. On the other hand, we have $R\left(\bigcup_{i=1}^{k} S_{1+n_{i}}, C_{4}\right) \geq \sum_{i=1}^{k} n_{i}+k+1$ (by Lemma 2.1). The assertion follows.

Theorem 2.3. Let $n_{i}$ be natural number for $i=1,2, \ldots, k$ and $n_{i} \geq n_{i+1} \geq 3$ for every $i$. If $n_{i}$ is odd and $2 n_{i+1} \geq n_{i}$ for every $i$, then $R\left(\bigcup_{i=1}^{k} S_{n_{i}}, W_{4}\right)=$ $R\left(S_{n_{k}}, W_{4}\right)+\sum_{i=1}^{k-1} n_{i}$ for $k \geq 1$.

Proof. Let $n_{i}$ be odd and $2 n_{i+1} \geq n_{i}$ for every $i$. Consider $F \cong K_{-1+\sum_{i=1}^{k} n_{i}} \cup$ $K_{n_{k}-1}$. Clearly, the graph $F$ has order $-2+2 n_{k}+\sum_{i=1}^{k-1} n_{i}$, without containing $\sum_{i=1}^{k} S_{n_{i}}$ and $\bar{F}$ contains no $W_{4}$. Hence,

$$
R\left(\bigcup_{i=1}^{k} S_{n_{i}}, W_{4}\right) \geq-1+2 n_{k}+\sum_{i=1}^{k-1} n_{i} .
$$

To obtain the Ramsey number we use an induction on $k$. For $k=1$, we have $R\left(S_{n_{1}}, W_{4}\right)=2 n_{1}-1$ (by Theorem 1$)$. For $k=2$, we show that $R\left(S_{n_{1}} \cup S_{n_{2}}, W_{4}\right)=$ $2 n_{2}-1+n_{1}=R\left(S_{n_{2}}, W_{4}\right)+n_{1}$.

Let $F_{1}$ be a graph with $\left|F_{1}\right|=2 n_{2}-1+n_{1}=2 n_{1}-1+2 n_{2}-n_{1}$. Assume that $\bar{F}_{1}$ contains no $W_{4}$. We show that $F_{1}$ contains $S_{n_{1}} \cup S_{n_{2}}$. Since $2 n_{2} \geq n_{1}$, then $\left|F_{1}\right| \geq 2 n_{1}-1$. By Theorem $1, F_{1}$ contains $S_{n_{1}}$. Write $L=F_{1} \backslash S_{n_{1}}$. Thus $|L|=2 n_{2}-1$, such that $L$ contains $S_{n_{2}}$. Hence, $F_{1}$ contains $S_{n_{1}} \cup S_{n_{2}}$. Therefore, $R\left(S_{n_{1}} \cup S_{n_{2}}, W_{4}\right) \leq 2 n_{2}-1+n_{1}$.

Suppose the theorem holds for every $r<k$. Let $F_{2}$ be a graph of order $-1+2 n_{k}+\sum_{i=1}^{k-1} n_{i}$. Suppose $\overline{F_{2}}$ contains no $W_{4}$. By the assumption, $F_{2}$ contains $\bigcup_{i=1}^{k-1} S_{n_{i}}$. Let $L^{\prime}=F_{2} \backslash \bigcup_{i=1}^{k-1} S_{n_{i}}$. Thus $\left|L^{\prime}\right|=2 n_{k}-1$. Since $\overline{L^{\prime}}$ contains no $W_{4}$, then by Theorem 1, $L^{\prime} \supset S_{n_{k}}$. Hence, $F_{2}$ contains $\bigcup_{i=1}^{k} S_{n_{i}}$. Therefore, we have

$$
R\left(\bigcup_{i=1}^{k} S_{n_{i}}, W_{4}\right)=-1+2 n_{k}+\sum_{i=1}^{k-1} n_{i}=R\left(S_{n_{k}}, W_{4}\right)+\sum_{i=1}^{k-1} n_{i} .
$$

\section{References}

[1] Baskoro, E. T., Hasmawati, Assiyatun, H., "The Ramsey Numbers for Disjoint Unions of Trees", Discrete Math, 306 (2006), 3297-3301.

[2] Baskoro, E. T., Surahmat, Nababan, S. M., dan Miller, M., (2002), "On Ramsey Numbers for Tree versus Wheels of Five or Six Vertices", Graph Combin., 18, 717 - 721.

[3] Burr, S. A., Erdös, P. and J. H. Spencer, "Ramsey Theorem for Multiple Copies of Graphs", Trans. Amer. Math. Soc., 209 (1975), 87-89.

[4] Chvátal, V. and Harary, F., "Generalized Ramsey Theory for Graphs, III: Small off-Diagonal Numbers", Pacific. J. Math., 41(1972), 335-345.

[5] Hasmawati, Assiyatun, H., Baskoro, E. T. and Salman, A. N. M., "Complete Bipartite Ramsey Numbers", Utilitas Math., 78(2008), 129-138. 
[6] Hasmawati, Assiyatun, H., Baskoro, E. T. and Salman, A. N. M., "The Ramsey Numbers for Complete Bipartite Graphs", Proceedings of the first International Conference on Mathematics and statistics, ICOMS-1, June 19-21 (2006), Bandung Indonesia, to appear.

7] Parsons, T. D., "Ramsey Graphs and Block Designs", J. Combin. Theory, Ser. A, 20 (1976), 12-19.

[8] Radziszowski, S. P., "Small Ramsey Numbers", The Electronic Journal of Combinatorics, July (2004) \#DS1.9, http://www.combinatorics.org/

[9] Surahmat and Baskoro, E. T., "On The Ramsey Number of a Path or a Star versus $W_{4}$ or $W_{5}$ ", Proceedings of the 12-th Australasian Workshop on Combinatorial Algorithms, Bandung, Indonesia, July 14-17 (2001), 165-170. 